\title{
Durability evaluation of carbon steel AISI1045 coated diamond-like carbon film using an atmospheric controlled IH-FPP system for pretreatment
}

\author{
H. Akebono ${ }^{1}$, M. Furukawa ${ }^{2}$, J. Komotori ${ }^{2}$ \& A. Sugeta ${ }^{1}$ \\ ${ }^{1}$ Department of Mechanical Science and Engineering, \\ Hiroshima University, Japan \\ ${ }^{2}$ Keio University, Japan
}

\begin{abstract}
Diamond-like carbon (DLC) films are well known for their excellent tribological properties; however, poor adhesion limits the practical applications of DLC films. In order to clarify the effect of atmospheric controlled IH-FPP (AIH-FPP) treatment for pretreatment on durability and adhesion of carbon steel AISI1045 coated DLC films, wear tests were carried out with a focus on the coating damage and delamination behavior. A Cr particle which indicates high chemical affinity to carbon which constitutes the DLC films was selected as shot material for the AIH-FPP treatment, and AIH-FPP was performed with two types of treatment conditions; the one generates the $\mathrm{Cr}$ transferred layer and the other generates the $\mathrm{Cr}$ diffused layer on the substrate surface. After AIH-FPP treatment, DLC films were coated on them by using an unbalanced magnetron sputtering (UBMS) method to a thickness of $2 \mu \mathrm{m}$. The specimens which have a $\mathrm{Cr}$ diffused layer at substrate surface and DLC films on it indicated low friction coefficient and maintained the excellent wear properties in the long-term region compared with practical DLC coated specimens. Consequently, it can be concluded that AIH-FPP with Cr particle is appropriate pretreatment before the coating process to achieve high durability and adhesion.
\end{abstract}

Keywords: diamond-like carbon, atmospheric IH-FPP, Cr diffused layer, friction coefficient, adhesion. 


\section{Introduction}

In recent years, diamond-like carbon (DLC) films [1-6] have attracted much attention in many industrial fields because of their properties, high hardness, chemical inertness, biocompatibility. Especially, DLC films are well known for their excellent tribological properties, so DLC films are attractive coating processes to achieve energy savings and $\mathrm{CO}_{2}$ emissions reduction. However, achieving higher adhesion of DLC films is an important task because poor adhesion between the films and the substrate limits the practical applications of DLC films.

In our previous study, we developed a surface treatment system that combined a high-frequency induction-heating (IH) system with FPP under controlled process atmosphere (referred to as AIH-FPP). AIH-FPP can generate a shot particle diffused layer, not only a transferred layer on a metal substrate [7-10]. This system has possibility to achieve the high adhesion strength compared with practical coating process by applying the $\mathrm{Cr}$ particle which indicates high chemical affinity to carbon which constitutes the DLC films as shot material. So, in this study, in order to improve the adhesion strength of DLC films, AIH-FPP was applied for pretreatment before coating process. Furthermore, the durability of carbon steel coated DLC film using AIH-FPP for pretreatment was examined experimentally.

\section{Specimens and experimental method}

The material (substrate) used in this study was a medium carbon steel (AISI1045) having a carbon content of $0.45 \%$. Table 1 presents its chemical composition. After being machined into a cylinder-shaped specimen (Fig. 1), the specimen surface was polished using SiC paper (\#320-\#1200). Figure 2 shows a schematic illustration of the AIH-FPP system. The specimen was set into the heating coil and the atmosphere in the chamber was replaced by supplying argon gas through the FPP nozzle. After the oxygen meter indicated $0.0 \%$, Cr shot particles (30-50 $\mu \mathrm{m}$ in diameter) were peened by the AIH-FPP system at $1173 \mathrm{~K}$ in an argon atmosphere. AIH-FPP condition is shown in Figure 3 and Table 2. In this study, 2 types of specimens which have different $\mathrm{Cr}$ layer were prepared; $\mathrm{Cr}$ transferred layer and Cr diffused layer on the specimen surface. We refer to the specimens with $\mathrm{Cr}$ transferred layer and $\mathrm{Cr}$ diffused layer as $F P P(T)$ series and $F P P(D)$ series. In addition, for comparison specimens, we prepared substrates which had not been performed AIH-FPP treatment (Virgin series). After AIHFPP process, all specimens were coated with DLC films using unbalanced magnetron sputtering (UBMS) to a thickness of $2 \mu \mathrm{m}$ (Cr interlayer $1 \mu \mathrm{m}+\mathrm{DLC}$ layer $1 \mu \mathrm{m})$. We refer to coated specimens as $F P P(T) / D L C, F P P(D) / D L C$, and Virgin/DLC series.

The microstructure of each specimen surface was observed by using a Scanning Electron Microscope (SEM) and Laser microscope. Cr transferred layer and diffused layer at specimen surface generated by AIH-FPP were examined by using an Energy Dispersive X-ray spectroscopy (EDX). Wear tests 
was carried out using a pin-on-disc wear testing machine without lubricating oil at room temperature (opponent material, $\mathrm{Al}_{2} \mathrm{O}_{3}(\phi=9.525 \mathrm{~mm}$ ); load, $9.8 \mathrm{~N}$; wear speed, $300 \mathrm{~mm} / \mathrm{min}$ ) to evaluate the durability of each DLC coated specimen. After wear tests, the wear surfaces were observed carefully using SEM and EDX to identify the condition of DLC films.

Table 1: $\quad$ Chemical composition of substrate AISI1045 (mass \%).

\begin{tabular}{cccccccccccc}
\hline $\mathrm{C}$ & $\mathrm{Si}$ & $\mathrm{Mn}$ & $\mathrm{P}$ & $\mathrm{S}$ & $\mathrm{Ni}$ & $\mathrm{Cr}$ & $\mathrm{Mo}$ & $\mathrm{Cu}$ & $\mathrm{Ti}$ & $\mathrm{Al}$ & $\mathrm{Fe}$ \\
\hline 0.45 & 0.20 & 0.71 & 0.018 & 0.026 & 0.04 & 0.13 & 0.01 & 0.09 & 0.002 & 0.002 & Bal. \\
\hline
\end{tabular}

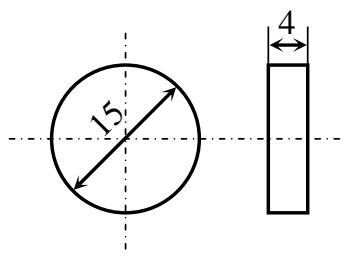

Figure 1: $\quad$ Specimen configuration.

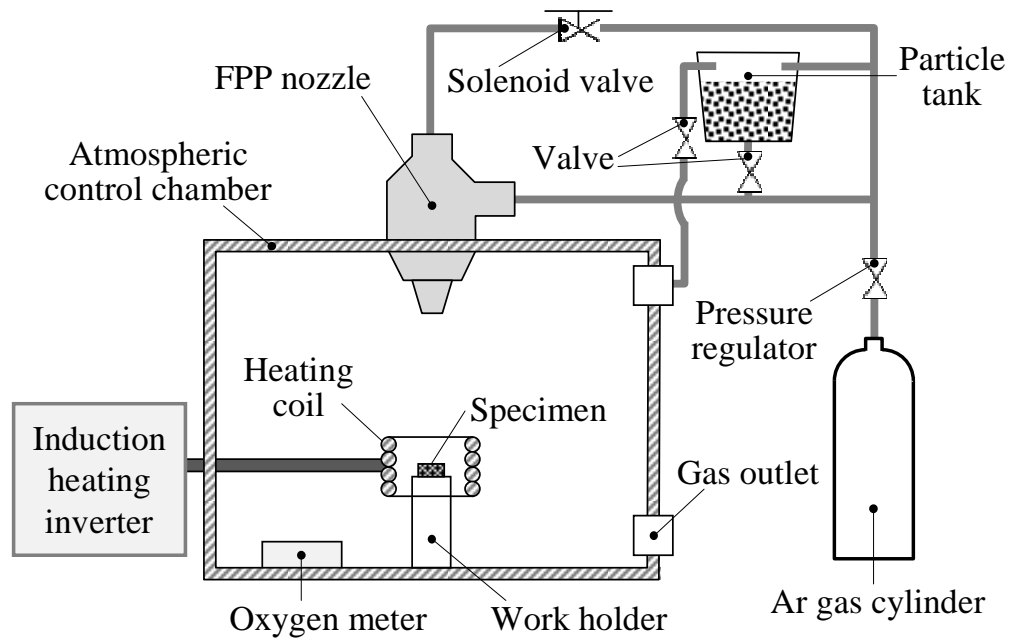

Figure 2: $\quad$ Schematic illustration of AIH-FPP system. 


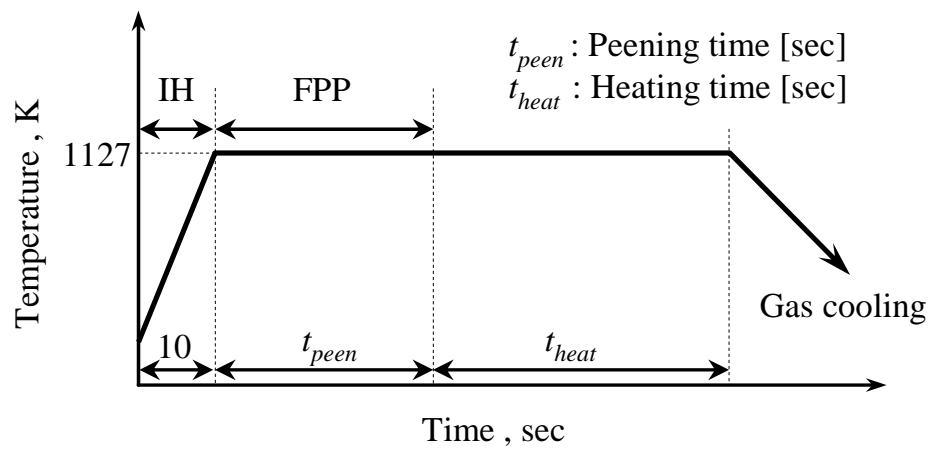

Figure 3: Thermal condition of AIH-FPP treatment.

Table 2: $\quad$ AIH-FPP treatment.

\begin{tabular}{|c|c|c|c|c|c|}
\hline & $\begin{array}{c}\text { Shot } \\
\text { material }\end{array}$ & $\begin{array}{c}\text { Treatment } \\
\text { temperature } \\
{[\mathrm{K}]} \\
\end{array}$ & $\begin{array}{l}\text { Peening } \\
\text { pressure } \\
{[\mathrm{MPa}]}\end{array}$ & $\begin{array}{c}\text { Peening time } \\
t_{\text {peen }} \\
{[\text { sec }]} \\
\end{array}$ & $\begin{array}{c}\text { Heating time } \\
t_{\text {heat }} \\
{[\text { sec }]}\end{array}$ \\
\hline$F P P(T)$ & \multirow{2}{*}{$\mathrm{Cr}$} & \multirow{2}{*}{1127} & \multirow{2}{*}{0.3} & \multirow{2}{*}{30} & 0 \\
\hline$F P P(D)$ & & & & & 60 \\
\hline
\end{tabular}

\section{Results and discussion}

\subsection{Observation results of surface layer modified by AIH-FPP treatment}

Figure 4 and 5 show the appearances of each specimen after AIH-FPP treatment and Virgin series and surface roughness of each specimen measured using a laser microscope. It is observed that surface roughness of both specimens which was performed AIH-FPP treatment indicated high value compared with Virgin series. Next, chromium layers generated by AIH-FPP treatment of both series were identified by observing cross-section of $F P P(T)$ and $F P P(D)$ series using SEM and EDX. Upper figures of figure 6 show the SEM image of cross-section, and lower figures show the distribution of iron, chromium, and oxygen elements, respectively as red, green, and blue points. Chromium was partly detected at surface in $\operatorname{FPP}(T)$ series. On the other hand, $F P P(D)$ series has a mixture layer both iron and chromium through the inside of substrate. These results implied that chromium layer at specimen surface was generated according to our request. 


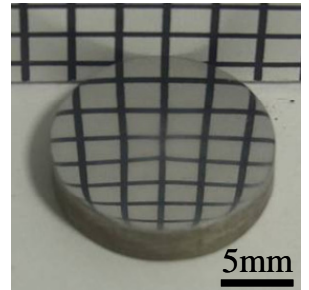

(a) Virgin

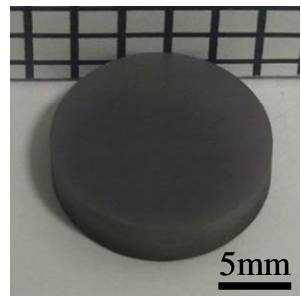

(b) $F P P(T)$

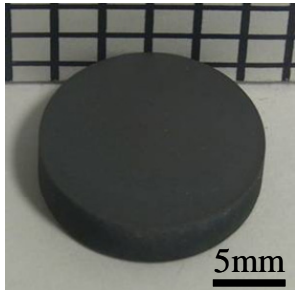

(c) $F P P(D)$

Figure 4: Macroscopic observation of specimens.

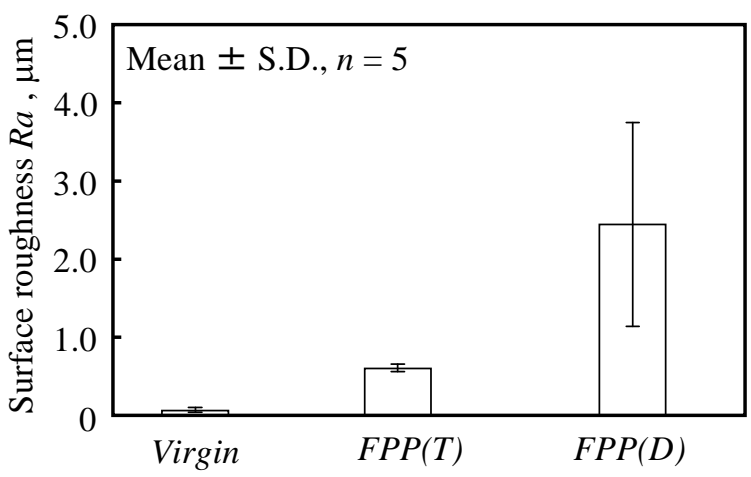

Figure 5: $\quad$ Surface roughness of specimens.

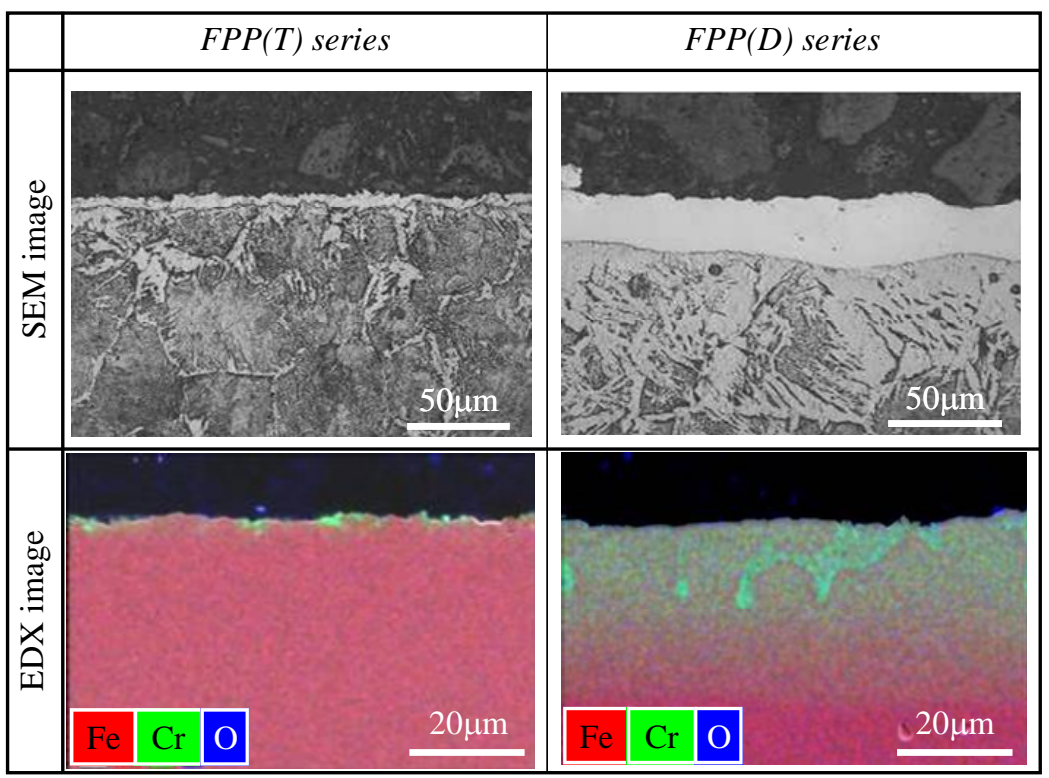

Figure 6: $\quad$ Longitudinal SEM and EDX maps of AIH-FPP treated specimens. 


\subsection{Durability evaluation of DLC films by wear test}

Figure 7 presents results of wear tests. In the case of both coated specimen, the friction coefficient of both series ranged 0.3 to 0.5 , and the values were about three or four times higher than that of Virgin/DLC series. On the other hand, In the case of Virgin/DLC series, its friction coefficient was stabilized at about 0.1 soon after starting the wear tests because of the existence of DLC films at surface. However, the value rapidly rose up at 8,000 wear cycles then it indicates the same value of both coated specimen.

Next, in order to examine the reason for wear results, the wear trace after wear tests (27,000 cycles) was observed using SEM and EDX(Figure 8). The left figures show SEM images and the right figures show the distribution of iron, carbon, and chromium elements, respectively as red, blue, and green points. The wear trace to a width of $600 \mu \mathrm{m}$ was observed in Virgin/DLC series, and iron which is main component of substrate was strongly detected there. This implied that DLC film at the surface of Virgin/DLC series was removed by friction loading then substrate was exposed absolutely. It can be thought that such delamination of DLC films was occurred at about 8,000 cycles considering from Fig. 7 because of the poor adhesion. Next, in the case of FPP(T)/DLC series, iron was partly detected but not all region in its wear trace. These results imply that DLC film was locally delaminated by friction loading, however the most film was remained through the wear tests. Consequently, the rough surface of both coated specimens shown in Fig.5 lead the higher the friction coefficient even though $\mathrm{Cr}$ layer generated by AIH-FPP treatment can improve the adhesion strength.

These results mentioned above suggest that it is necessary to reduce the surface roughness created by AIH-FPP treatment in order to achieve excellent friction coefficient over the long term.

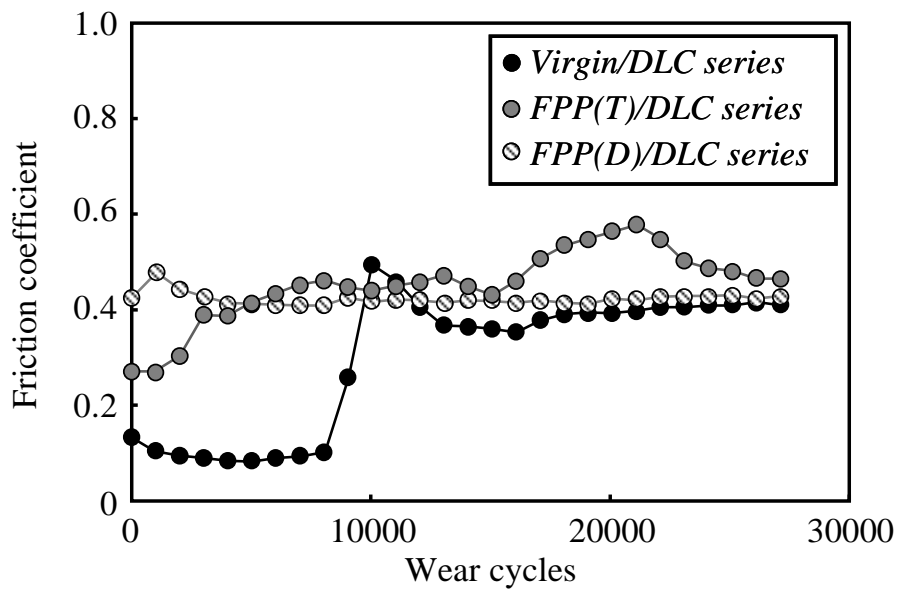

Figure 7: Results of wear tests. 


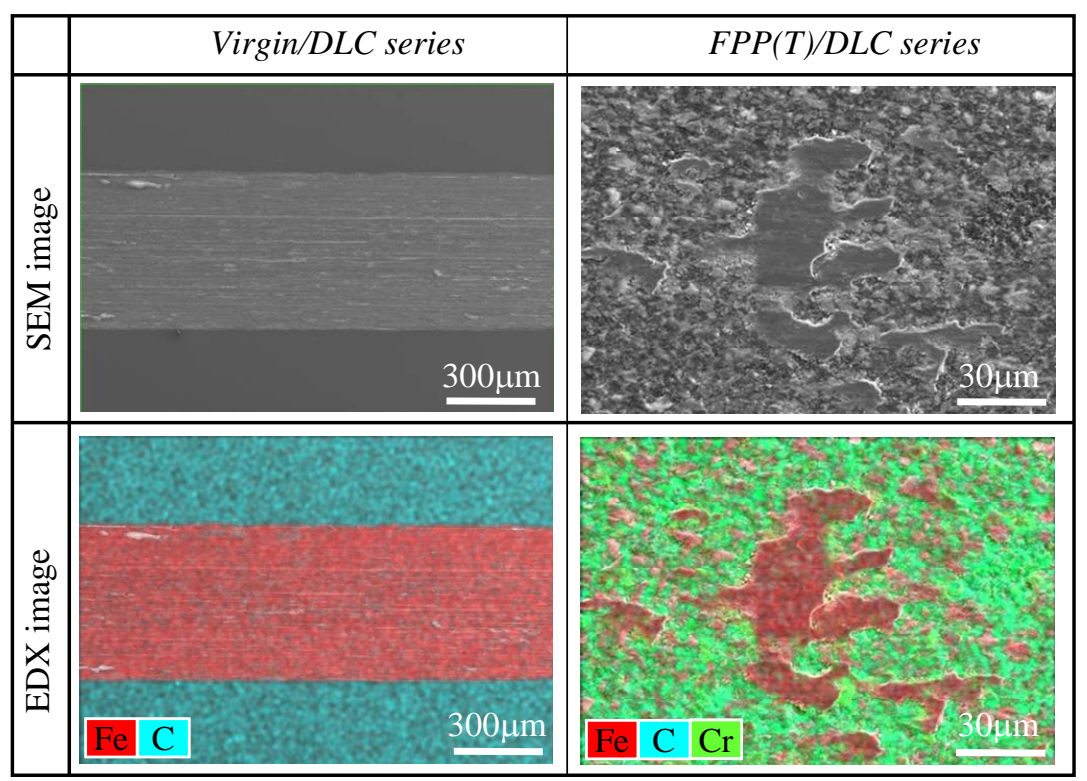

Figure 8: Wear trace after wear tests.

\subsection{New DLC coated specimen removed the rough surface created by AIH-FPP treatment}

In this section, in order to achieve DLC coated specimen which indicates excellent wear properties over the long term without delamination, the rough surface with micro dimples created by AIH-FPP treatment was removed by polishing, and then DLC films were coated on the flat surface. In addition, AIHFPP treatment can generate two types of chromium layer, $\mathrm{Cr}$ transferred layer and $\mathrm{Cr}$ diffused layer. However, $\mathrm{Cr}$ diffused layer was selected for the new specimen mentioned above because $\mathrm{Cr}$ transferred layer was absolutely removed by polishing process after AIH-FPP treatment. We refer to this new specimen as $F P P(D) / p o l i s h / D L C$ series.

Figure 9 shows the microstructure of $\operatorname{FPP}(D)$ series before and after the polishing process to remove the rough surface. It is observed that polishing process can remove the rough surface with remaining the chromium diffused layer generated by AIH-FPP process at specimen surface. From these observation results, $\operatorname{FPP}(D) /$ polish/DLC series is expected to achieve the low friction coefficient and excellent durability on friction loading. So, additional wear tests were carried out.

Figure 10 presents results of wear tests. For comparison, the results of Virgin/DLC series were also plotted in this figure. It is clear that $\operatorname{FPP}(D) /$ polish/DLC series indicated low friction coefficient from starting to the end of the wear tests without delamination as expected. 


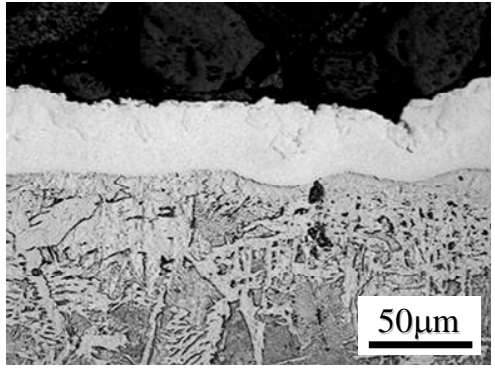

(a) Before polishing $(F P P(D)$ series $)$

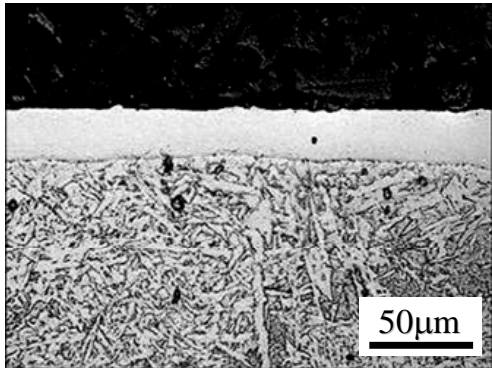

(b) After polishing $(F P P(D) /$ polish series $)$

Figure 9: $\quad$ SEM images of $F P P(D)$ series before and after polishing process.

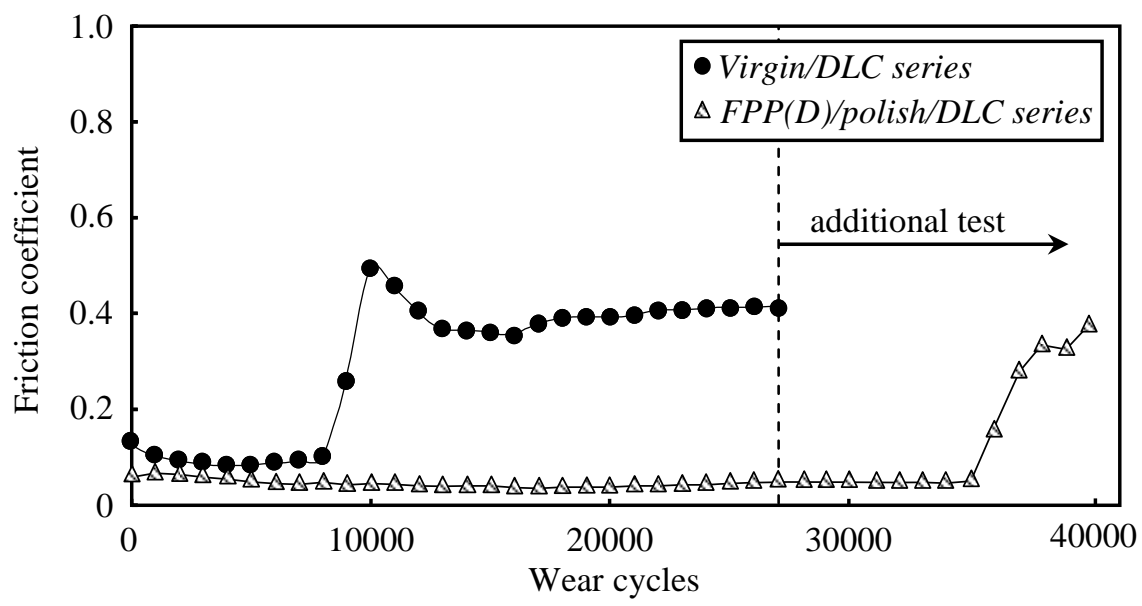

Figure 10: Results of wear tests.

Next, in order to identify DLC films after wear tests, the wear trace of FPP(D)/polish/DLC series after wear tests (27,000 cycles) was observed using SEM and EDX (Fig. 11). The left figures show SEM images and the right figures shows the distribution of iron and chromium, respectively as red and blue points.

It is observed that the wear trace width of $F P P(D) /$ polish/DLC series was narrower than that of Virgin/DLC series as shown in Fig. 8, furthermore DLC film remained at surface through the wear tests because carbon elements were locally detected in the wear trace even though iron elements which means no DLC films was locally detected there. In addition, in order to identify the durability of $F P P(D) /$ polish/DLC series, more additional wear tests were continued until the delamination of DLC films. Rapidly increasing the friction coefficient led by the coating delamination was observed at 35,000 wear cycles. Therefore, AIH-FPP treatment suggested in this study can improve the durability of DLC films on friction loading significantly compared with that of practical DLC coated specimen. 


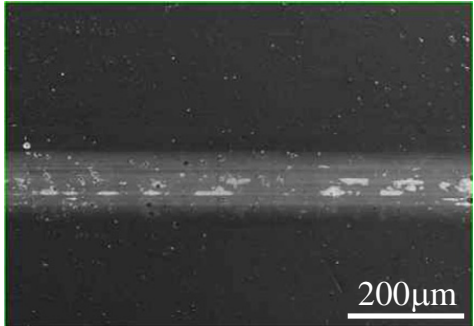

(a) SEM image

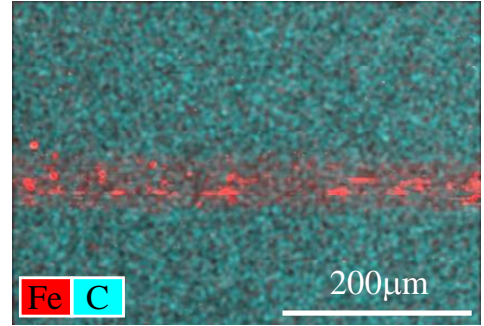

(b) EDX image

Figure 11: Wear trace after wear tests $(F P P(D) / p o l i s h / D L C$ series $)$.

\section{Conclusions}

In order to improve the adhesion strength of DLC films, atmospheric controlled IH-FPP system was applied for pretreatment before coating process. The wear properties and durability of carbon steel coated DLC film using AIH-FPP for pretreatment was examined by pin-on-disc wear testing machine experimentally. The results are summarized as follows:

1. AIH-FPP system can generate $\mathrm{Cr}$ transferred layer and $\mathrm{Cr}$ diffused layer by controlling the process condition. However, it is necessary to remove the rough surface to apply the AIH-FPP system for pretreatment before DLC coating process because the rough surface created by AIH-FPP treatment lead the high friction coefficient on friction loading.

2. By coating DLC films on Cr diffused layer with polishing process to remove rough surface, it was possible to improve the adhesion strength between the DLC films and the substrate. Consequently, these DLC coated specimen indicated excellent wear properties over the long term compared with practical DLC coated specimen.

\section{References}

[1] Kalin, M. and Vižintin, J., The tribological performance of DLC coatings under oil-lubricated fretting conditions, Tribology International, 39(10), pp. 1060-1067, 2006.

[2] Sui, J.H., Gao, Z.Y., Cai, W. and Zhang, Z.G., Corrosion behavior of NiTi alloys coated with diamond-like carbon (DLC) fabricated by plasma immersion ion implantation and deposition, Materials Science and Engineering: A, 452, pp. 518-523, 2007.

[3] Aizawa, T., Akebono, H. and Suzuki, H., The Tribological and Fatigue Properties of Steel modified by Hybrid Surface Modification Combining Super Rapid Induction Heating and Quenching with DLC Coating, Transactions of the Japan Society of Mechanical Engineers series A, 73(731), pp. 803-808, 2007. 
[4] Kameyama, Y., Niwa, A. and Komotori, J., Effect of fine particle bombardment treatment on tribological properties and adhesion of DLC film coated on SCM440 steel, Journal of the Society of Materials Science, 56(5), pp. 453-459, 2007.

[5] J. Choi, J., Nakao, S., Kim, J., Ikeyama, M. and Kato, T., Corrosion protection of DLC coatings on magnesium alloy, Diamond and Related Materials, 16(4), pp. 1361-1364, 2007.

[6] Ni, W., Cheng, Y.T., Weiner, A.M. and Perry, T.A., Tribological behavior of diamond-like-carbon (DLC) coatings against aluminum alloys at elevated temperatures, Surface and Coatings Technology, 201(6), pp. 32293234, 2006.

[7] T. Ito, S. Kikuchi, Y. Kameyama, J. Komotori, K. Fukazawa, Y. Misaka and K. Kawasaki, Development of an Atmospheric Controlled IH-FPP Treatment System and Its Application to Structural Steel, Journal of the Japan Institute of Metals, 74(8), pp. 533-539, 2010.

[8] T. Fukuoka, Y. Ujiie, J. Komotori, K. Fukazawa, Y. Misaka and K. Kawasaki, Effects of processing parameters on characteristics of surface modified layers generated by atmospheric controlled IH-FPP system, Procedia Engineering, 10, pp. 1503-1508, 2011.

[9] T. Fukuoka, S. Kikuchi, J. Komotori, K. Fukazawa, Y. Misaka and K. Kawasaki, Effect of Shot Particle on the Mechanism of Creating a Modified Layer by Atmospheric Controlled IH-FPP Treatment, Journal of the Japan institute of metals, 75(7), pp. 372-378, 2011.

[10] A. Sasago, S. Kikuchi, Y. Kameyama, J. Komotori, K. Fukazawa, Y. Misaka and K. Kawasaki, Development of IH-FPP processing system by induction heating and surface modification of S45C steel, Journal of the Japan Institute of Metals, 72(5), pp. 347-352, 2008. 